\title{
Solar heat gains through train windows: a non-negligible contribution to the energy balance
}

\author{
Olivia Bouvard $\mathbb{D} \cdot$ L. Burnier - P. Oelhafen - A. Tonin • \\ P. Wüst • F. Sidler • G. Zweifel • A. Schüler
}

Received: 18 February 2016 / Accepted: 26 February 2018

(C) Springer Science+Business Media B.V., part of Springer Nature 2018

\begin{abstract}
The sector of transportation accounts for about one third of the total energy consumption in Switzerland. A monitoring campaign of the energy consumption of a regional train revealed the critical energyconsuming systems. Heating, cooling and ventilation were identified as major consumers. Windows are a source of non-controlled heat transfer. In summer, it may result in overheating leading to larger cooling loads while in winter, it is an important source of thermal losses. Selective double glazing and solar protection coatings can reduce these effects. Angular-dependent optical properties of a selective double glazing have been measured, and the solar heat gain coefficient ( $\mathrm{g}$ value) was determined. An estimation of the solar gains received by a panoramic waggon was performed using the monitored solar irradiation and the measured properties of the glazing. These data were compared to the
\end{abstract}

O. Bouvard $(\bowtie) \cdot$ L. Burnier $\cdot$ A. Schüler

Ecole Polytechnique Fédérale de Lausanne, Solar Energy and

Building Physics Laboratory, EPFL LESO-PB, Lausanne,

Switzerland

e-mail: olivia.bouvard@epfl.ch

P. Oelhafen - A. Tonin

Departement of Physics, University of Basel, Basel, Switzerland

P. Wüst

Ecotrans GmbH, Rheineck, Switzerland

F. Sidler · G. Zweifel

Lucerne University of Applied Sciences and Arts, School of

Engineering and Architecture, Horw, Switzerland heating and cooling energy consumption monitored in this waggon. Solar gains were found to be in the same order of magnitude that the heating energy during some sunny days. They were also compared to the estimated thermal losses through the glazing and the entire envelope. These results show that the solar gains play a nonnegligible role in the energy balance of the waggon. Furthermore, thermal simulations were performed to evaluate the solar gains in different conditions. It showed that 7 to $13 \%$ of energy can be saved using the glazing adapted to the climatic conditions. In addition, improving the thermal insulation of the train envelope or equipping the train with an efficient heat recovery system can lead to significant energy savings.

Keywords Energy efficiency P Public transportation · Railway · Solar heat gains · Energy consumption · HVAC · Heating · Cooling · Selective glazing · Solar protection $\cdot$ Solar irradiation

\section{Introduction}

In Switzerland, the first sector in terms of energy consumption is transportation. It accounted for more than one third $(35.4 \%)$ of the total energy consumption in 2012, followed by domestic use (28.4\%) and industries (18.7\%) (Bundesamt für Statistik 2014). With the increase in population and in distance travelled, the demand for transport is rising, leading to larger emissions of carbon dioxide. Resulting congestion and pollution 
are a problem in main urban zones. Public transportation can help to reduce the environmental impact of mobility. The railway network in Switzerland is dense and well connected. Trains offer a low-carbon transport solution. However, in order to stay competitive, high energy efficiency should be sought. Research and development mainly focused on drive system and fuel efficiency (Tzeng 2005; Daldaban and Ustkoyuncu, 2010; Hoffrichter et al., 2012), aerodynamics (Raghunathan et al., 2002; Wood 2004) and energy recovery (Barrero et al., 2008; González-Gil et al., 2013; Hamacek et al., 2014). Until recently, auxiliary energy consumers were not thoroughly studied (González-Gil et al., 2014). However, a detailed study of individual energy consumers can identify critical elements. Such an analysis was performed and indicates that the heating and cooling systems have a high impact. Data obtained from the monitoring of a Swiss regional fixed-formation train with three coaches (RABe 525-006) is presented. This study focuses on the transparent part of the envelope, especially on the solar gains. The Glacier Express (GEX) is a panoramic train travelling the Swiss Alps with a large surface of glazing. It is an interesting model system for the study of glazing-related issues. A spectrally selective double glazing from this train is analysed; angular-dependant optical properties are given, and the solar factor (also called $g$ value) is determined experimentally. The solar gains are estimated using the isotropic diffuse sky assumption and compared to the heating and cooling loads for one waggon of the Glacier Express train. Finally, the choice of a low ( $g=0.3)$ or high $(g=0.6)$ solar factor is simulated in different scenarios including other refurbishment measures such as a better thermal insulation or the installation of a heat recovery system.

\section{Methods}

Energy metering in short distance train

An in-depth monitoring campaign of energy consumers in a Swiss regional train was performed. Data was acquired during regular services over an extended period of time which spans over all seasons. The electric consumers monitored in this train (Nina type, RABe 525-006) are detailed in Table 1. The electric consumption was measured with 13 industrial energy meters from EMH with an M-Bus readout (DIZD651DMi and
Table 1 Electric consumption measuring points

\begin{tabular}{|c|c|}
\hline Circuits & Electric consumers \\
\hline $\begin{array}{l}\text { Main circuits } \\
\text { Traction }\end{array}$ & $\begin{array}{l}\text { Total energy received } \\
\text { from pantograph } \\
\text { Traction energy } \\
\text { Recovered traction energy }\end{array}$ \\
\hline $\begin{array}{l}\text { Auxiliary circuits } \\
\text { HVAC }\end{array}$ & $\begin{array}{l}\text { Heating energy } \\
\text { Ventilation energy } \\
\text { Cooling energy } \\
\text { DC energy/battery charging }\end{array}$ \\
\hline $\begin{array}{l}\text { Other consumers not belonging } \\
\text { to major HVAC consumers } \\
\text { (not measured individually) }\end{array}$ & $\begin{array}{l}\text { Ventilation fans main } \\
\text { transformer (2) } \\
\text { Oil pump main transformer } \\
\text { Ventilation fan (traction) } \\
\quad \text { power inverters } \\
\text { Ventilation fan traction motors } \\
\text { Air compressor } \\
\text { Pedal heating drivers' cabs, } \\
\text { sockets drivers' cabs, } \\
\text { flapper valves, servo-motors } \\
\text { (air recirculation) }\end{array}$ \\
\hline
\end{tabular}

DIZD665DMi). One meter type is measuring the onephase current and voltage of trains with passive transducers $(16.7 \mathrm{~Hz})$, and the other type is measuring threephase alternating current and voltage $(50 \mathrm{~Hz})$. The accumulated value of each energy meter was recorded and sent to the data server every minute.

In addition, climatic data was monitored. The outside temperature is measured by two sensors. They are placed between waggons in a manner that prevent faulty readings due to direct sunlight. In addition, the temperature at a critical point was measured in a roof-mounted box. All temperature sensors are combined with sensors for relative humidity. Solar radiation on the vertical planes was measured using two pyranometers (SP Lite 2 from Kipp \& Zonen) located slightly above the windows. Inside the train, the following elements were measured: temperature of passengers' and drivers' compartments, brightness (Lux sensor), $\mathrm{CO}_{2}$ concentration and volatile organic compounds (VOC). The indoor sensors were located above the seats in the middle of the waggon, approximately 3 to $4 \mathrm{~m}$ from the doors. GPS coordinates were also recorded. Thus, elevation, velocity and directions of motion are known. Data was transferred automatically by GSM data modem to a data 
Fig. 1 Regional train equipped with energy meters, sensors for ambient and outdoor conditions and GPS. Values are transmitted to a server by mobile communication for an easy access and analysis of the data

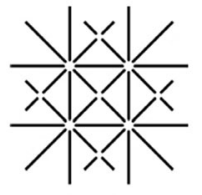

UN I $B A S E$

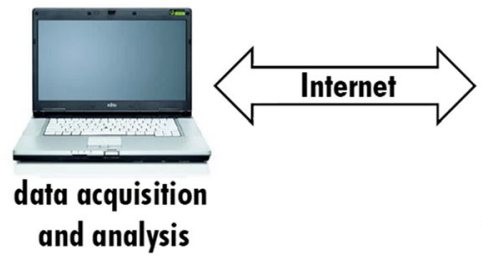

data server

antenna

(a)

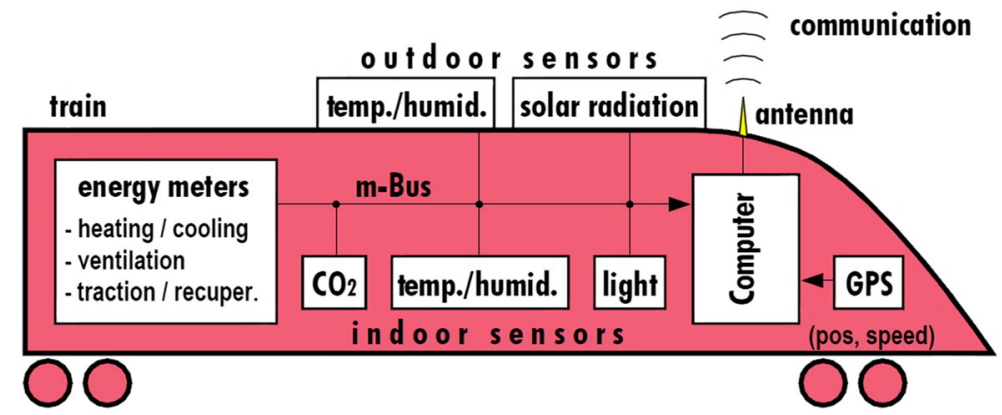

server (Opit e3m dataCenter). Figure 1 depicts the global system.

In a similar manner, a panoramic waggon, the Glacier EXpress (GEX), was monitored. On this waggon, the heating, ventilation and air conditioning (HVAC) and other secondary consumers as described in Table 1 as well as climatic data were monitored, whereas the traction energy was not recorded.

Angular-dependent optical properties of insulating double glazing

Using the window test bench originally developed at University of Basel (Steiner et al., 2005) and now installed at EPFL/LESO-PB in Lausanne, it was possible to measure the transmittance and reflectance at angles of incidence from $0^{\circ}$ to $75^{\circ}$. This experimental set-up is composed of a light source, a support able to carry and rotate an up-to-scale double glazing, a receiver collimator and a Zeiss diode array spectrometer as depicted in Fig. 2. The front diffusor plate of the light source provides a rectangular area $\left(25 \times 38 \mathrm{~cm}^{2}\right)$ of homogeneous diffuse radiation in the near UV, visible and near infrared wavelength range. A homogeneous intensity distribution over the front diffusor plate is required in order to account correctly the radiation passing the double glazing indirectly by one or several internal reflections between the glass panes. Furthermore, a high temporal stability of the radiation intensity is obtained by making use of stabilised DC power supplies. The receiver collimator consists of a quartz lens with an aperture of $28 \mathrm{~mm}$ and a focal length of $76 \mathrm{~mm}$. For transmittance, the collimator is placed in line with the light source. For reflectance measurements, the collimator can be moved to have the same light path length for each angle. Spectral intensities are measured for wavelengths ranging from 350 to $2150 \mathrm{~nm}$ (UV-VisNIR).

These values are used to determine the coefficient of solar direct energy transmission $\tau_{\mathrm{e}}$ and visible light transmission $\tau_{\mathrm{v}}$ according to Eqs. 1 and 2, respectively (EN 410, 2011).

$\tau_{\mathrm{e}}=\frac{\sum_{\lambda=350 \mathrm{~nm}}^{2100 \mathrm{~nm}} S_{\lambda} \tau(\lambda) \Delta \lambda}{\sum_{\lambda=350 \mathrm{~nm}}^{2100 \mathrm{~nm}} S_{\lambda} \Delta \lambda}$

where $S_{\lambda}$ is the relative spectral distribution of the solar radiation, $\tau(\lambda)$ is the spectral transmittance of the glazing and $\Delta \lambda$ is the wavelength interval.

$\tau_{v}=\frac{\sum_{\lambda=380 \mathrm{~nm}}^{780 \mathrm{~nm}} D_{\lambda} \tau(\lambda) V(\lambda) \Delta \lambda}{\sum_{\lambda=380 \mathrm{~nm}} D_{\lambda} V(\lambda) \Delta \lambda}$

where $D_{\lambda}$ is the relative spectral distribution of illuminant D65, $\tau(\lambda)$ is the spectral transmittance of the glazing, $V(\lambda)$ is the spectral luminous efficiency for photopic vision defining the standard observer for photometry and $\Delta \lambda$ is the wavelength interval. 

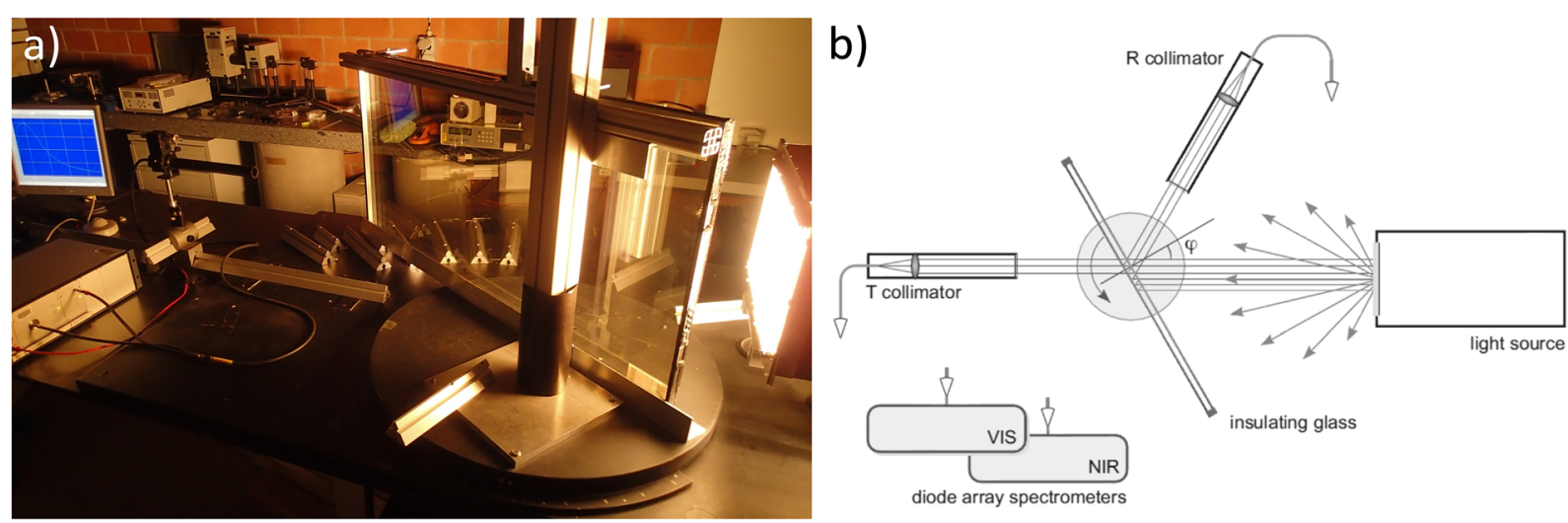

Fig. 2 Windows test bench used to measure the spectral reflectance and transmittance as a function. a Photograph showing the setup. Windows are carried by a rotating holder allowing to vary the angle of incidence of the light. The collimator is connected to

The solar direct reflectance $\rho_{\mathrm{v}}$ and $\rho_{\mathrm{e}}$ can be calculated in a similar manner, using Eqs. 1 and 2, by replacing the spectral transmittance $\tau(\lambda)$ with the spectral reflectance $\rho(\lambda)$. The solar direct absorptance, $\alpha_{\mathrm{e}}$, can be found using the Relation (3).

$\tau_{\mathrm{e}}+\rho_{\mathrm{e}}+\alpha_{\mathrm{e}}=1$

Angular-dependent solar gain factor of insulating double glazing

In order to obtain the internal heat load, the solar factor $g$ is necessary; it is defined by Eq. 4 .

$g(\varphi)=\tau_{\mathrm{e}}(\varphi)+q_{\mathrm{i}}$

Where $\tau_{\mathrm{e}}(\varphi)$ is the coefficient of solar direct energy transmission for an angle $\varphi$, and $q_{\mathrm{i}}$ is the secondary internal heat transfer factor. $q_{\mathrm{i}}$ represents the part of energy absorbed by the glass and reemitted as heat on the interior side. In the steady state, the solar direct energy absorption (Eq. 5) is divided into the secondary internal and external heat transfer factors $q_{\mathrm{i}}$ and $q_{\mathrm{e}}$.

$\alpha_{\mathrm{e}}=q_{\mathrm{i}}+q_{\mathrm{e}}$

The angular dependent solar gain was determined using the method developed by Reber et al. (Reber et al., 2005). This method is based on the measurement of the external and internal surface temperature of the double glazing while being under a beam from a solar simulator. The light source of the solar simulator is a

an optical fibre and can be positioned at different angles and optical paths. b Diagram depicting the different components reproduced from Steiner et al., 2005with the authorization of the author

water-cooled xenon arc lamp (1000 W). A spectral distribution similar to that of solar radiation is achieved by the means of filters. The elevation of the surface temperature of the glazing is related to the heat flows from the surfaces towards the ambient according to heat transport theory for free convection. The secondary internal heat transfer factor $q_{\mathrm{i}}$ depends on the external and internal heat transfer coefficients $h_{\mathrm{e}}$ and $h_{\mathrm{i}}$, respectively, that are fixed in standards such as EN 410 (EN410) to $h_{\mathrm{e}}=23 \mathrm{~W} /\left(\mathrm{m}^{2} \mathrm{~K}\right)$ and $h_{\mathrm{i}}=8 \mathrm{~W} /\left(\mathrm{m}^{2} \mathrm{~K}\right)$. Since we are not performing the experiment under these conditions (that would require a forced convection of the order of $4 \mathrm{~m} / \mathrm{s}$ at the outer surface and an internal surface temperature increment of $12 \mathrm{~K}$ with respect to ambient), $q_{\mathrm{i}}$ is computed for standard conditions. To determine the $g$ value, a calculated $U$ value is used as an input. The thermal performances of a double glazing can be estimated using the standards developed for the buildings such as the EN 673 for the calculation of the $U$ value (or thermal transmittance) (EN 673, 2011). This calculation takes into account the conduction through the glass and the air gap, the convection by calculating a Nusselt number and the radiation considering the emissivity of each surface.

Thermal simulations

Thermal simulations, using IDA Indoor Climate and Energy (EQUA Simulation AB, 2016), were performed to evaluate different scenarios regarding the train envelope and heating systems. Standard climatic data from Rome and Samedan were used. A 3D model of the train 
was created based on the existing and calibrated model of the "Flirt" train, constructed in 2007 and run by the Südostbahn company. The basic data of the train model are shown in Table 2. The model was adapted to the roof part in order to consider the influence of the panoramic windows (roof lights) as shown in Fig. 3. The passenger numbers considered in these simulations were defined in dependence of the $\mathrm{CO}_{2}$ concentrations from the measurements carried out in 2015. The energy losses due to door openings at the stops were not considered.

\section{Results}

Energy consumption of HVAC systems

Data were acquired on the fixed-formation regional train (Nina RABe 525-006) during 365 consecutive days (from 01 April 2011 to 31 March 2012). The distance travelled during this period is $132,500 \mathrm{~km}$. The diagram in Table 3 represents the individual energy consumption of each component with respect to the total energy consumption.

The energy of train is provided by a catenary. It supplies at acceleration the gross energy and recovers energy during braking (recovered energy). The net energy represents what is really consumed by the train (gross energy minus recovered energy). The percentages in Table 3 were calculated relatively to the net energy consumed by the train over a year. In the studied train, HVAC systems account for $31.8 \%$ of the net total energy consumption. In addition, $13.8 \%$ of the energy consumption is dedicated to other consumers such as pumps, fans and air compressor. The present data has been recorded over a complete annual period and therefore span over all seasons. Other old trains in Switzerland were monitored and indicate similar proportion (Isenschmid et al., 2013). Heating amounts to more than

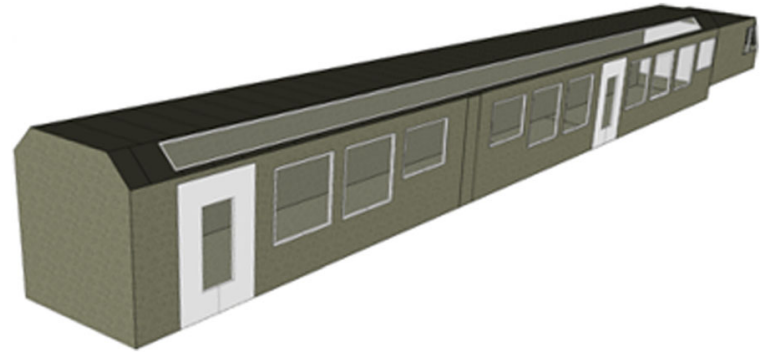

Fig. 3 Schematic drawing of the simulated train

one quarter of the total energy consumption. Considering the current construction details of the train envelope and the heating control system, there is a vast potential to increase energy efficiency. Nowadays, the energetic issue is taken into consideration and recent trains have a better design regarding the energy consumption.

Optical and thermal performances of a selective glazing

Glazing is an important part of the train envelope. It provides a visual connexion with the exterior. In winter, high thermal losses through the windows and the opaque part but also due to infiltrations gives a high heating load. Furthermore, the cold surface of the window can be a source of discomfort. Double glazing with a low emissivity coating, also called energy saving glazing or selective glazing, can improve the thermal performances. Spectrally selective glass presents a different behaviour in the infrared region and in the visible part of the spectrum. An increase of the thermal insulation of the window can be obtained by a low emissivity coating. This transparent metallic coating reduces the emissivity of the glass pane thus limiting the thermal losses through radiation. The thermal performances of a window are described by the thermal transmittance also called $U$ value. For a double glazing with a first glass pane of $4 \mathrm{~mm}$, an air gap of $14 \mathrm{~mm}$ and a second glass pane

Table 2 Data of the adapted train model used for the simulation

\begin{tabular}{ll}
\hline Size & Length $63.1 \mathrm{~m}$, width $2.6 \mathrm{~m}$ \\
Areas & Floor $164 \mathrm{~m}^{2}$, roof $188 \mathrm{~m}^{2}$, walls $310 \mathrm{~m}^{2}$, windows $105 \mathrm{~m}^{2}$, doors $30 \mathrm{~m}^{2}$ \\
Windows & $U$ value glass $1.6 \mathrm{~W} / \mathrm{m}^{2} \mathrm{~K}$, frame proportion $10 \%$, frame $U$ value $2 \mathrm{~W} / \mathrm{m}^{2} \mathrm{~K}$ \\
Passengers & $455(212 \mathrm{sitting}, 243 \mathrm{standing})$ \\
Air flow rates & Max. air exchange rate $13(1 / \mathrm{h})$, volume flow rate per person $11 \mathrm{~m} / \mathrm{h}$ \\
Mechanical systems & Radiators; combined air heating and cooling \\
Average $U$ value of the train envelope $U_{\text {train }}$ & $1.5 \mathrm{~W} / \mathrm{m}^{2} \mathrm{~K}$ (including walls, roof, floor, windows and thermal bridges) \\
\hline
\end{tabular}


Table 3 Relative energy consumption of subsystems for the train RABe 525-006

Net energy: 613'648 kWh 100\%

\author{
Traction energy: 333'946 kWh \\ $54.4 \%$ \\ HVAC: $195^{\prime} 204 \mathrm{kWh}$ \\ $31.8 \%$
}

Other consumers: $84^{\prime} 498 \mathrm{kWh}$

$13.8 \%$
Heating energy: 161'424 kWh (26.3\%)

Cooling energy: 19'212 kWh (3.1\%)

Ventilation energy: 14'568 kWh (2.4\%)

Recovered energy: 244'270 kWh

of $5 \mathrm{~mm}$, the calculated $U$ value is $2.77 \mathrm{~W} /\left(\mathrm{m}^{2} \cdot \mathrm{K}\right)$ according to the calculation described in the standard EN 673. For the same thicknesses with a coating with an emissivity of $3 \%$ towards the air gap, the calculated $U$ value is $1.44 \mathrm{~W} /\left(\mathrm{m}^{2} \cdot \mathrm{K}\right)$. Therefore, the thermal losses through the windows are almost divided by a factor 2 when a low emissivity coating is used. Furthermore, the reduction of solar gains can be achieved by a coating blocking a part of the nonvisible solar spectrum (near infrared), this is called solar protection. The Glacier Express (GEX) being a panoramic train travelling the Swiss Alps, it has a large surface of glazing to allow passenger to enjoy the view over the mountains. On each side of the waggon, as depicted in Fig. 4, there are six tilted windows $\left(1 \mathrm{~m}^{2}\right)$ sitting on top of six large vertical windows $\left(3.74 \mathrm{~m}^{2}\right)$. The windows are not operable and connected to the frame with glue. The windowto-"wall" ratio (WWR) is about $34 \%$. For comparison, the regional train described in Fig. 1 as a WWR of $11 \%$.

A glazing similar to the one used in this train was studied. Optical properties and the solar factor have been measured. Results of the transmittance measurements are presented in Fig. 5a. The transmittance of the studied glazing exhibits a selective behaviour. The proportion of energy transmitted in the visible part of the spectrum $(380-800 \mathrm{~nm})$ is higher than in the nearinfrared (NIR 800-2500 nm). A peak of transmittance is observed for all angles of incidence between 480 and $580 \mathrm{~nm}$. In addition, the transmittance decreases as the incidence angle increases. At normal incidence, the maximum transmittance is almost $67 \%$ at $515 \mathrm{~nm}$, while at low incidence angle $\left(75^{\circ}\right)$, it is down to $32 \%$. Figure $5 \mathrm{~b}$ depicts the angular spectral reflectance of the same double glazing. The reflectance spectrum (Fig. 5b) also shows a selective behaviour. In the visible range, reflection is higher than in the near-infrared (400 to $750 \mathrm{~nm}$ ). As the incidence angle increases, a higher proportion of the light is reflected. Transmittance and reflectance spectra indicate the presence of a low emissivity and a solar protection coating.

The same double glazing was exposed to a solar simulator. The outer and inner surface temperatures as well as the ambient temperature were recorded and are displayed in Fig. 6a. Using these temperatures, it was possible to determine the coefficient of internal heat transfer $\left(q_{\mathrm{i}}\right)$ and was also possible to calculate the solar factor $(g)$.

The factors of total energy transmittance $\left(\tau_{\mathrm{e}}\right)$ and visible transmittance $\left(\tau_{\mathrm{v}}\right)$ have been calculated using respectively the spectrum of global solar radiation AM1.5 $\mathrm{g}$ and the sensitivity curve $V(\lambda)$ of the human eye (daylight conditions, photopic vision). Figure $6 \mathrm{~b}$ presents $\tau_{\mathrm{e}}, \tau_{\mathrm{v}}$ and the experimental solar factor as a function of the incidence angle, $g(\varphi)$. These results indicate that the Glacier Express is equipped with windows featuring solar protection and a low-emissivity coating. The solar transmission, reflection and absorption factors $\left(\tau_{\mathrm{e}}, \rho_{\mathrm{e}}, \alpha_{\mathrm{e}}\right)$, the visible transmission factor $\left(\tau_{\mathrm{v}}\right)$ and the $g$ value as a function of the angle of incidence are detailed in Table 4.

Estimation of glazing impact on heating and cooling load

For a better understanding of the high consumption of HVAC, different measurements and calculations have been done to estimate the impact of the solar gain through the windows in the Glacier EXpress (GEX) train. The estimation is based on one waggon of the GEX (without counting the traction energy). The total irradiation was measured on site with three pyranometers which were placed on top and on either side of the train waggon. If incident isotropic diffuse sky radiation is integrated over all angles (including ground 


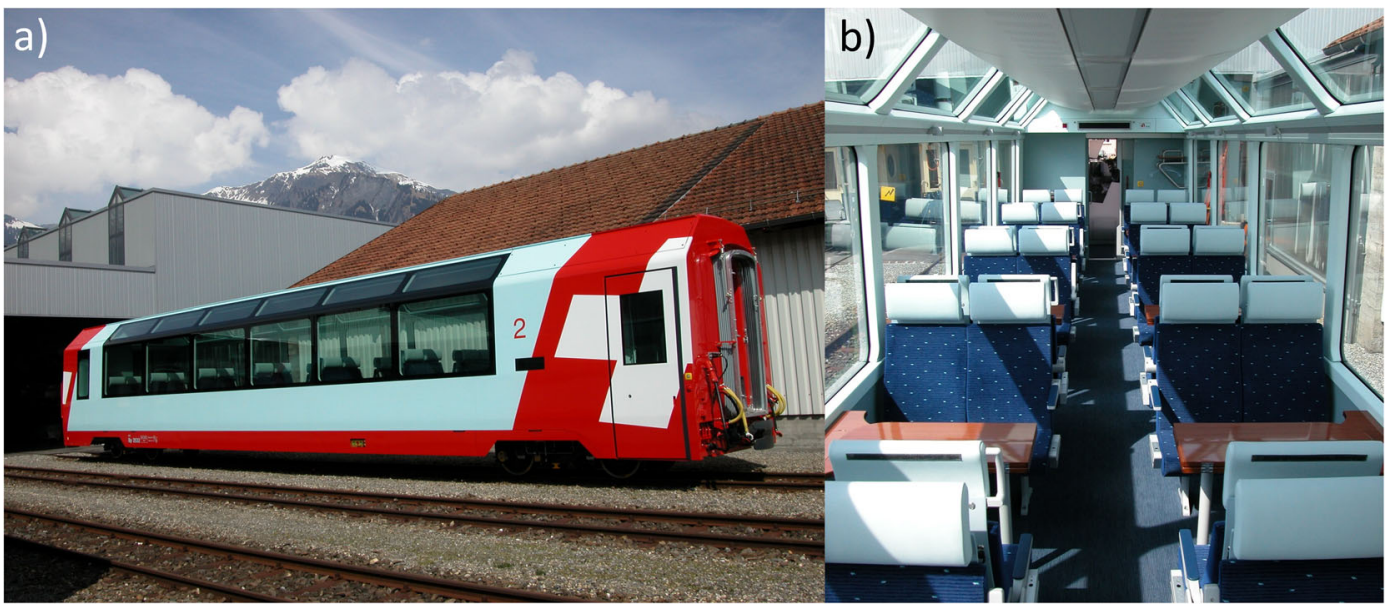

Fig. 4 Photograph of the panoramic waggon of the GEX train $\mathbf{a}$ from outside and $\mathbf{b}$ from inside

reflected diffuse radiation), it has been shown to have an effective incidence angle of approximately 60 degrees for vertical and horizontal isotropic surfaces (Duffie and Beckman, 1991).

The angular dependent solar factor $g(\varphi)$ was determined for the glazing of the GEX train (see Table 4). Using these values and considering an isotropic diffuse sky, an effective $g$ value was calculated by integrated the measured $g(\varphi)$ on a half sphere. The effective solar factor was found to be $g_{\text {eff }}=0.428$. This value corresponds to the solar factor $g$ measured for an angle of $57.5^{\circ}$. This mean effective angle is close to the Duffie et al. calculation, but it takes into consideration the optical properties of the glass.

Therefore, for a simple estimation of the solar gains, the total surface of the windows has been considered, and a $g$ value of $g_{\text {eff }}=0.428$ was used. Due to the assumption of isotropic irradiance, an error in the order of $\pm 10 \%$ has to be considered. Figures 7 and 8 display

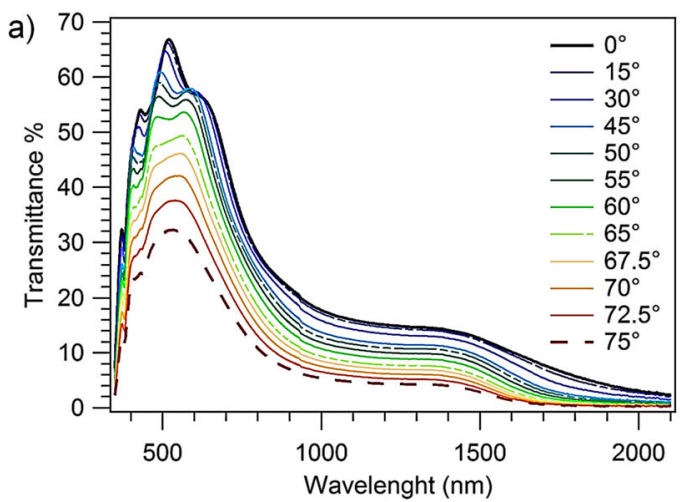

the estimated solar gains along with the measured energy consumption of the heating and cooling and of the sum of the secondary consumers (HVAC and other consumers as detailed in Table 1).

Figure 7 focuses on two single days, one cloudy (Fig. 7b) and one sunny (Fig. 7d) in order to show the hourly variation of the heating and cooling load along with the solar gains. For the cloudy day (Fig. 7b), the chart shows a high energy consumption of the heating system (around $120 \mathrm{kWh}$ ); also, a small amount of energy is saved due to the solar gains (around $20 \mathrm{kWh}$ ). For a sunny day (Fig. 7d), the heating system runs in the morning to bring the temperature of the cabin up to a set point. During the afternoon, the heating system stops working, and the air conditioning system starts. The energy consumption of the cooling system has the same order of magnitude as the solar gains. We can also observe that the outside temperature is below the cabin set point of $20^{\circ} \mathrm{C}$ (Fig. $7 \mathrm{c}-\mathrm{d}$ ).

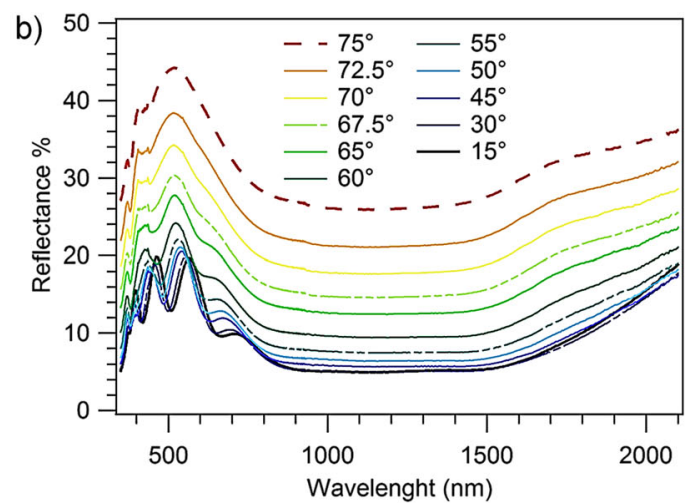

Fig. 5 a Spectral of transmittance $\tau(\lambda)$ depending on angle $\varphi$ of light incidence for GEX window. b Spectral reflectance $\rho(\lambda)$ depending on angle $\varphi$ of light incidence for GEX window 

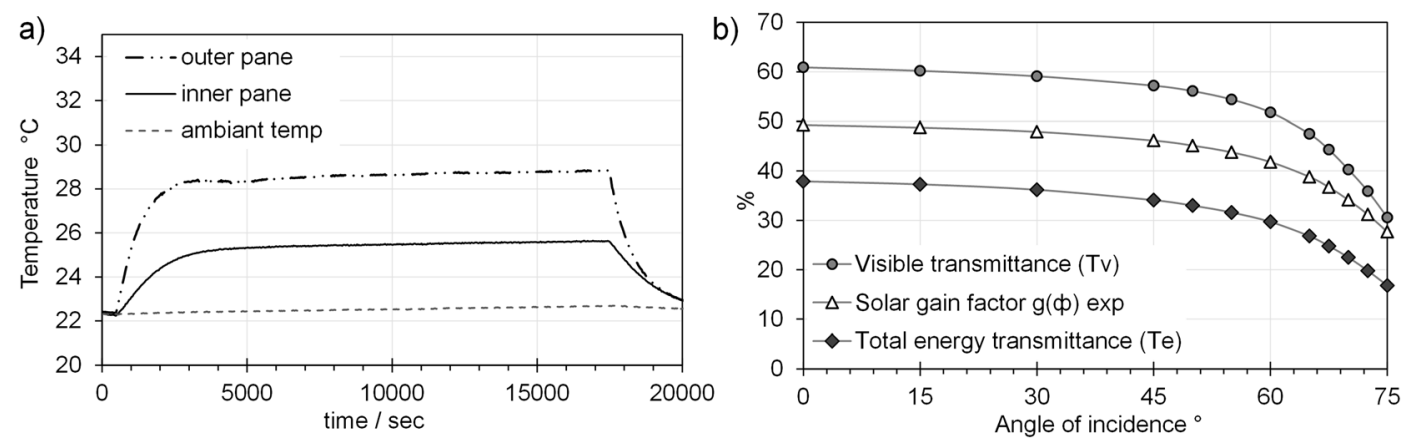

Fig. 6 a Heating and cooling curves of the interior and the exterior sides of the GEX window. b Visible transmittance $\left(\tau_{\mathrm{v}}\right)$, energy transmittance $\left(\tau_{\mathrm{e}}\right)$ and experimental $g$ factor $(g)$ depending on the angle of incidence $\varphi$

Then, this estimation has been performed for five different weeks throughout the year to estimate the importance of each parameter depending on the seasons. The results are presented in Fig. 8.

Regarding Fig. 8, the consumption of the air conditioning is correlated to the solar gain during five different times of the year. Moreover, during the winter period, the solar gain is low (100-200 kWh) compared to the heating consumption (1000-1200 kWh). The mean temperature difference $\Delta \bar{T}$ presented in Fig. 8 was calculated from the measured indoor and outdoor temperatures. Using this $\Delta \bar{T}$, the thermal losses through the glazing and through the full envelope were estimated, they are displayed in Table 5. For the glazing, the $U$ value of the glazing and the surface of glazing per waggon were used. For the envelope, the thermal losses were considered to be equal to the heating plus the solar gains in December where little cooling is used. From this assumption, an effective thermal loss coefficient

Table 4 Optical properties and solar gain factor of Glacier Express panoramic window from AGC

\begin{tabular}{llllllll}
\hline$\varphi\left(^{\circ}\right)$ & $\tau_{\mathrm{e}}$ & $\tau_{\mathrm{v}}$ & $\tau_{\mathrm{e}} / \tau_{\mathrm{v}}$ & $\rho_{\mathrm{e}}$ & $\alpha_{\mathrm{e}}$ & $g$ & $g / \tau_{\mathrm{v}}$ \\
\hline 0 & 0.38 & 0.61 & 0.62 & 0.10 & 0.52 & 0.49 & 0.81 \\
15 & 0.37 & 0.60 & 0.62 & 0.10 & 0.52 & 0.49 & 0.81 \\
30 & 0.36 & 0.59 & 0.61 & 0.10 & 0.54 & 0.48 & 0.81 \\
45 & 0.34 & 0.57 & 0.60 & 0.11 & 0.55 & 0.46 & 0.81 \\
50 & 0.33 & 0.56 & 0.59 & 0.12 & 0.55 & 0.45 & 0.80 \\
55 & 0.32 & 0.54 & 0.58 & 0.13 & 0.56 & 0.44 & 0.80 \\
60 & 0.30 & 0.52 & 0.57 & 0.15 & 0.55 & 0.42 & 0.81 \\
65 & 0.27 & 0.48 & 0.56 & 0.18 & 0.55 & 0.39 & 0.82 \\
67.5 & 0.25 & 0.44 & 0.56 & 0.21 & 0.54 & 0.37 & 0.83 \\
70 & 0.23 & 0.40 & 0.56 & 0.24 & 0.53 & 0.34 & 0.85 \\
72.5 & 0.20 & 0.36 & 0.55 & 0.28 & 0.52 & 0.31 & 0.87 \\
\hline
\end{tabular}

was defined and used to estimate the thermal losses through the envelope during the other weeks.

The ratio between the solar gains (shown in Fig. 8) and the thermal losses through the glazing was calculated (Table 5-column 3). It reveals that the windows have a positive energy balance during all the selected weeks except in December. The ratio between the solar gains and the thermal losses through the envelope was also calculated (column 4). It can be observed that in April, the solar gains amount to approximately half of the thermal losses of the envelope; in summer, it exceed the thermal losses, and therefore, air conditioning is needed. The solar gains represent 6 to $34 \%$ of the total energy consumption of the secondary consumers which was monitored during these weeks. These values show that the solar gains play a non-negligible role in the energy balance of the waggon.

\section{Thermal simulations}

Annual simulations were carried out on the adapted train model, considering internal heat gains from lighting, equipment and passengers. A set of cases with different combinations of climate, heat recovery in the ventilation system (HR), improved $U$ value of the train envelope $\left(\mathrm{U}_{\text {train }}\right)$, as shown in Table 6 were calculated and analysed for the evaluation of the energy impact of the $g$ value. Two climates were chosen to represent locations with both high solar irradiations, one with rather low temperatures in a mountain climate (Samedan, Switzerland) and one with warm outside temperatures in a southern location (Rome, Italy). The useful thermal energy for heating and cooling was taken as a result from the simulations. However, for a fair comparison, these values were transferred to electrical energy with the assumption that direct electric heating is used, 

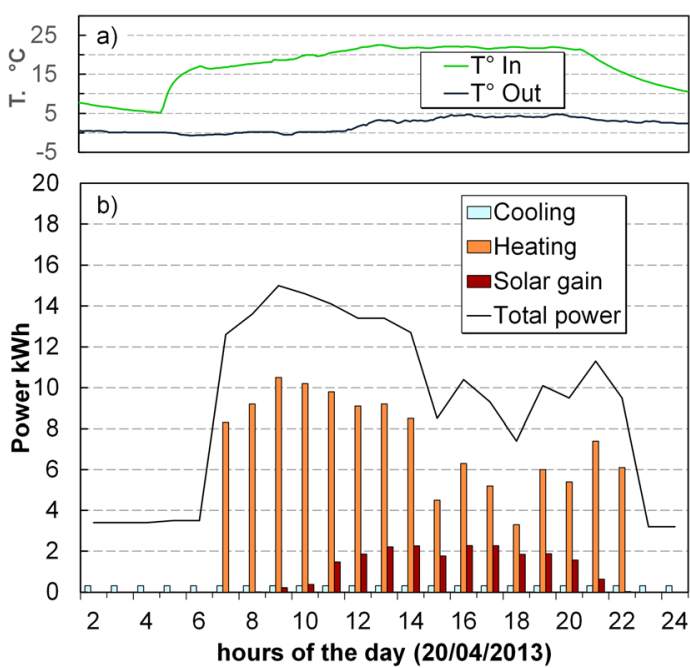

Fig. 7 Data measured from the Glacier Express waggon on two single days a, b 20 April 2013, c, d 25 April 2013. a, c Inside and outside temperature. $\mathbf{b}, \mathbf{d}$ Energy consumed by cooling (blue bar)

whereas the cooling has a seasonal energy efficiency ratio (SEER) of 2.0. Both assumptions are realistic in respect of current railway equipment technology.

The annual electrical energies for heating and cooling for the 12 cases, described in Table 6, are shown in Fig. 9. In Fig. 9a, which shows the results for the mountain climate, it can be observed that the heating demand is high (114 to $171 \mathrm{MWh} / \mathrm{a}$ ). The energy needed for cooling is comparatively low (1 to $6 \mathrm{MWh} / \mathrm{a}$ ). For the southern climate, displayed in Fig. 9b, the total energy is much lower (50 to $68 \mathrm{MWh} / \mathrm{a}$ ), with the energy for heating ranging from 30 to $55 \mathrm{MWh} / \mathrm{a}$. The cooling energy ranges from 9 to $19 \mathrm{MWh} / \mathrm{a}$ representing
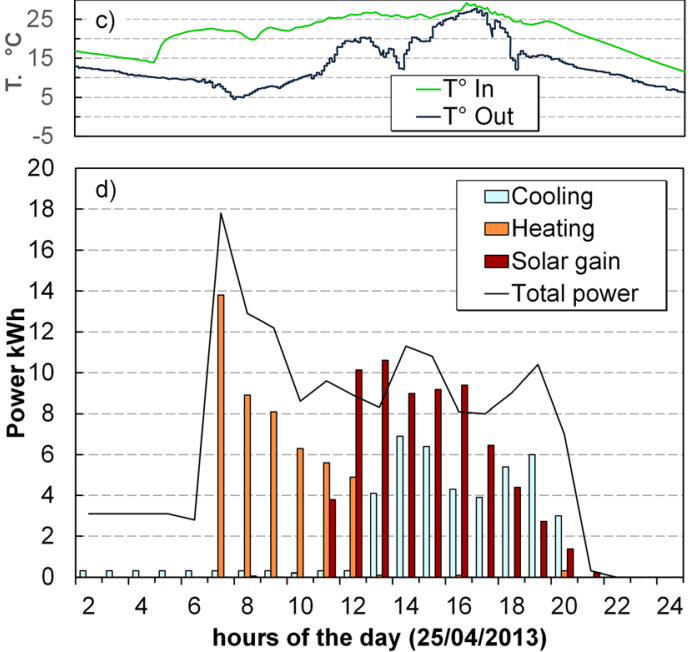

and heating (orange bar), secondary consumers (HVAC and other consumers) (black line) and estimation of solar gains (red bar)

between 15 and $40 \%$ of the annual electrical energy consumption for heating and cooling. Figure $9 a, b$ shows that for both climates, the reductions of the total energy consumption for heating and cooling due to the heat recovery or to the $U$ value of the train envelope are in the same order of magnitude. It can also be observed that the impacts of these two effects are larger than the impact of the $g$ value. The improvement of the $U$ value of the train can lead to 18 to $26 \%$ of annual electric energy savings whereas with a heat recovery system it can reach 25 to $32 \%$.

It can also be seen that for the southern climate, the energy needed for heating and cooling energy is

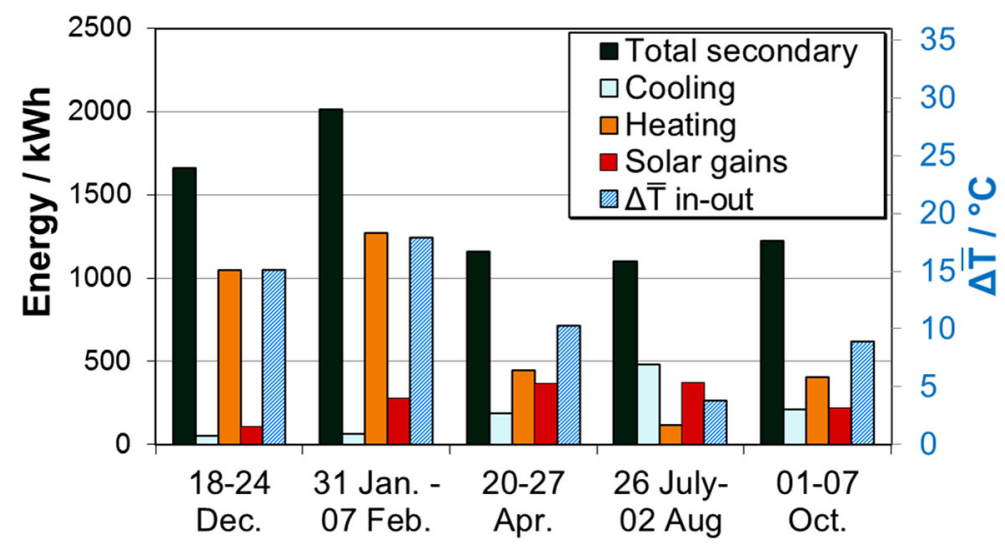

Fig. 8 Energy consumption of heating and cooling and the sum of HVAC and other consumers (total secondary) as measured during the monitoring campaign during 7-day period along the year and estimation of the solar gains during the same period according to the measured solar vertical radiation. The mean temperature difference $\Delta \bar{T}$ calculated from the measured indoor and outdoor temperatures is also reported 
Table 5 Solar gains compared thermal losses through the glazing area and the full envelope

\begin{tabular}{llllll}
\hline & $\begin{array}{l}\text { Thermal loss } \\
\text { glazing/kWh }\end{array}$ & $\begin{array}{l}\text { Thermal loss } \\
\text { envelope/kWh }\end{array}$ & $\begin{array}{l}\text { Solar gains/thermal } \\
\text { loss glazing }\end{array}$ & $\begin{array}{l}\text { Solar gains/thermal } \\
\text { loss envelope }\end{array}$ & $\begin{array}{l}\text { Solar gains/energy consumption } \\
\text { secondary consumers }(\%)\end{array}$ \\
\hline 18-24 December & 210 & 1150 & 0.5 & 0.1 & 6 \\
31 January to 07 February & 250 & 1370 & 1.1 & 0.2 & 14 \\
20-27 April & 140 & 780 & 2.6 & 0.5 & 32 \\
26 July to 02 August & 50 & 290 & 7.1 & 1.3 & 18 \\
01-07 October & 120 & 680 & 1.8 & 0.3 & 34 \\
\hline
\end{tabular}

always higher with a window $g$ value of 0.6 compared to a $g$ value of 0.3 . The decrease of heating energy due to higher solar heat gains with $g=0.6$ is overcompensated by the increase of cooling energy needs. This is generally different from the mountain climate, where the heating energy demand is much higher and the cooling is much lower. This effect is more clearly illustrated in Fig. 10, where the difference in electrical energy for heating and cooling between $g$ values of 0.6 and 0.3 is shown. For the cold mountain climate (Fig. 10a), the additional solar gains due to a $g$ value of 0.6 compared to a $g$ value of 0.3 help to reduce the total energy consumption by up to $7 \%$. However, for the southern climate (Fig. 10b), the annual energy consumption increases by up to $13 \%$ if a $g$ value of 0.6 is used for the windows. If other actions to reduce the thermal losses are implemented, such as heat recovery or better $U$ value of the train, then the effect is more pronounced.

\section{Discussion}

The detailed monitoring of trains revealed that secondary systems such as heating and air conditioning can account for more than one quarter of the total energy consumption of trains. In order to evaluate the impact of the solar gains, a window from a panoramic waggon was fully characterised. The glazing of the Glacier Express includes tinted glass and spectrally selective coating while regional trains usually do not. From the measured angular $g$ values and based on the assumption of perfectly isotropic irradiance, an effective solar factor of $g_{\text {eff }}=0.428$ was used. It was then used to determine the amounts of solar gains in a panoramic waggon. The solar gains were found to be in the same order of magnitude than the energy needed for cooling. These results are based on measured solar irradiation, temperatures and energy consumptions for specific days or weeks. The energy balance of the windows is positive

Table 6 Parameter used for the various simulated scenarios

\begin{tabular}{|c|c|c|c|c|c|}
\hline Climate & Scenario & Explanation & $\begin{array}{l}\mathrm{HR} \\
\%\end{array}$ & $\begin{array}{l}\mathrm{U}_{\text {train }} \\
\mathrm{W} / \mathrm{m}^{2} \mathrm{~K}\end{array}$ & $\begin{array}{l}\text { g-value } \\
-\end{array}$ \\
\hline \multirow[t]{6}{*}{ a) Samedan, Switzerland, mountain climate } & g0.3 U1.5 & Basis mountain & 0 & 1.5 & 0.3 \\
\hline & g0.6 U1.5 & & 0 & 1.5 & 0.6 \\
\hline & $\mathrm{g} 0.3 \mathrm{U} 1.0$ & Improved $U$ value $\left(U_{\text {train }}\right)$ & 0 & 1 & 0.3 \\
\hline & g0.6 U1.0 & & 0 & 1 & 0.6 \\
\hline & g0.3 HR & Heat recovery $75 \%$ (HR) & 0.75 & 1.5 & 0.3 \\
\hline & $\mathrm{g} 0.6 \mathrm{HR}$ & & 0.75 & 1.5 & 0.6 \\
\hline \multirow[t]{6}{*}{ b) Rome, Italy, southern climate } & g0.3 U1.5 & Basis southern & 0 & 1.5 & 0.3 \\
\hline & $\mathrm{g} 0.6 \mathrm{U} 1.5$ & & 0 & 1.5 & 0.6 \\
\hline & g0.3 U1.0 & Improved $U$ value $\left(U_{\text {train }}\right)$ & 0 & 1 & 0.3 \\
\hline & g0.6 U1.0 & & 0 & 1 & 0.6 \\
\hline & g0.3 HR & Heat recovery $75 \%(\mathrm{HR})$ & 0.75 & 1.5 & 0.3 \\
\hline & g0.6 HR & & 0.75 & 1.5 & 0.6 \\
\hline
\end{tabular}



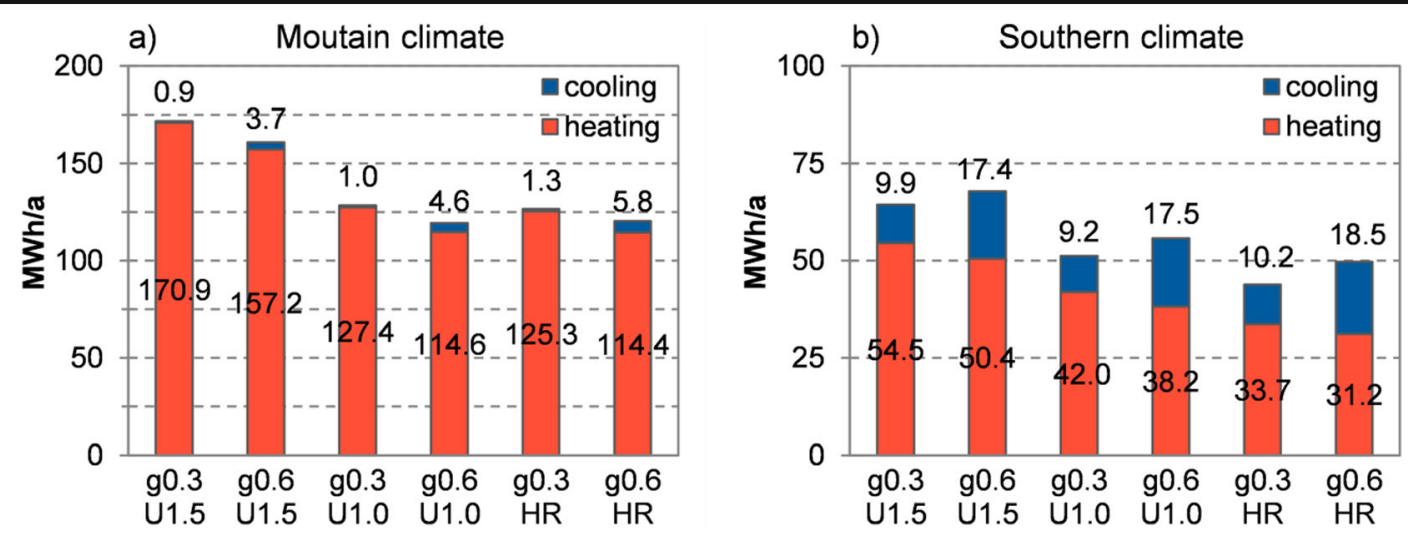

Fig. 9 Annual electrical energy for heating and cooling simulated for low and high $g$ value in the basis scenario, the one with improved insulation of the train envelope (U1.0) and the one with a heat recovery system (HR) for a the mountain climate and $\mathbf{b}$ the southern climate

during the studied weeks, expect in December. However, during spring and summer, the solar gains can be excessively high and lead to an increase in energy consumption by air conditioning. It was observed that during a sunny day in April, the heating can work in the morning and the air conditioning in the afternoon. A better regulation of the ventilation system should take advantage of the outside air when it is colder than the inside air. These estimations were performed using the isotropic sky approximation and an effective $U$ value based on the heating consumption.

Thermal simulations were then performed in order to assess the impact of glazing with high or low solar factor within different refurbishment scenarios such as a heat recovery system and an improved insulation of the train envelope. Two climates with high solar gains were considered, a cold mountain climate and a warm southern climate. For the mountain climate where cooling

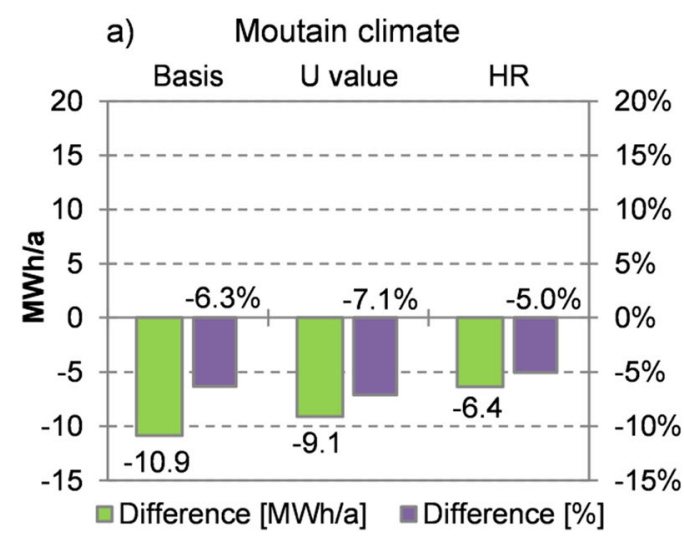

Fig. 10 Absolute and relative difference in annual energy for heating and cooling for a window $g$ value of 0.6 against a $g$ value of 0.3 for the base scenario, the one with improved insulation $(U$ needs are limited, it was found that a high solar factor ( $g=0.6)$ is energetically favourable with up to $7 \%$ savings compared to a glazing with $g=0.3$. In the southern climate, it was found that a glazing with a low solar factor $(g=0.3)$ was preferable and could lead to energy savings up to $13 \%$ compared to a glazing with $g=0.6$. Improving the average $U$ value from 1.5 to $1.0 \mathrm{~W} / \mathrm{m}^{2} \mathrm{~K}$ of the train envelope could lead to about $20 \%$ savings in annual electrical energy. In order to achieve a lower average $U$ value of the train, better or thicker insulation panels are needed along with a reduction of the thermal bridges. Besides, in some trains, uncoated double glazing is used. The use of lowemissivity coatings improve the insulation of the glazing by a factor two but reduce transmission of the microwaves for telecommunications (Bouvard et al., 2017). The solution is then to install repeaters or use a glazing with a special treatment (Burnier et al., 2017). Another

\section{b) Southern climate}

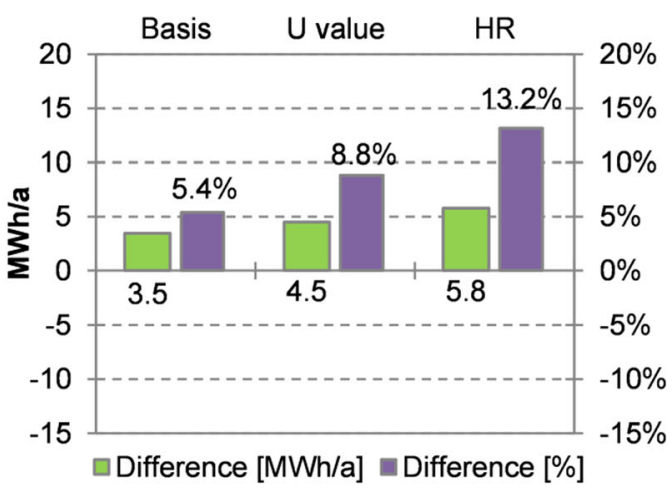

value) and the one with a heat recovery system (HR) for a the mountain climate and $\mathbf{b}$ the southern climate 


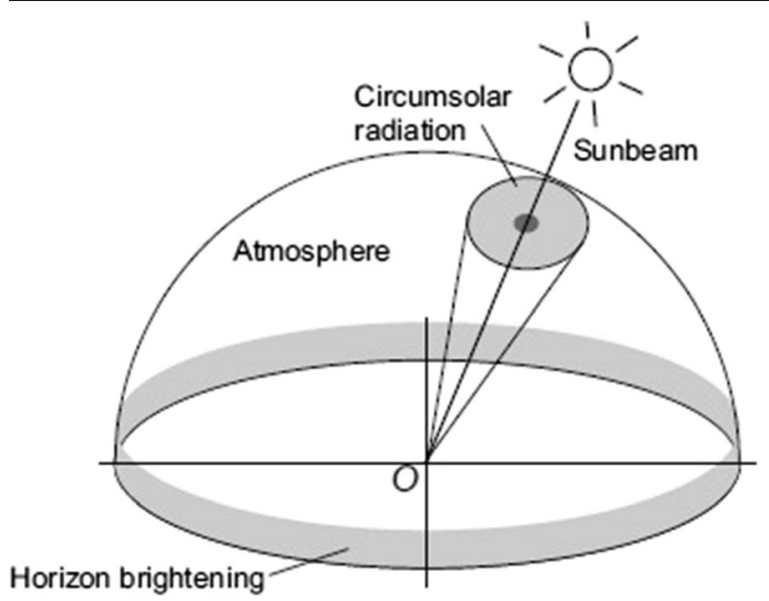

Fig. 11 Anisotropic diffuse sky model

solution can be to install a heat recovery system (efficiency $75 \%$ ) which could lead to about $30 \%$ energy savings. Furthermore, in the southern climate, we can observe that the choice of a solar protection for the glazing becomes more important with improved insulation of the train envelope or a heat recovery system. Therefore, improving the insulation or installing a heat recovery system leads to larger benefits than changing the solar factor glazing. However, replacing the glazing in order to use the solar factor adapted to the climate and to improve the thermal insulation if no coating were present is a maintenance operation that can be performed in shorter maintenance stops than the full refurbishment of the train.

To be used in thermal simulations, the climatic data coming from meteorological stations have to be split into diffuse and direct light. The usual way of generating it is to apply a model (Erbs et al., 1982) to the measured global horizontal radiation considering the split into diffuse and direct portions. In addition, for calculations taking into account different orientations and tilt angles, the model of (Perez et al., 1987), involving an anisotropic model for the diffuse sky with a $25^{\circ}$ circum solar aureole and a horizon band (Fig. 11), has proven to be appropriate.

On trains, the glass areas are considerably large and have the special feature of always sitting in opposite orientation. Also, the horizontal radiation is of minor importance. Therefore, it might be especially suitable to base the analysis on vertical radiation data measured on both sides of the train. In order to obtain the direct and diffuse portions from these data, a calculation model is developed. The fact that the two vertical sides of the train have exactly opposite orientation has the advantage that there is always one plane exposed to direct radiation. Therefore, the difference between the two measured radiations can be interpreted as the direct portion. In the case where the sun is on the roof (e.g. high in the sky or if the train is going exactly towards south), the sensors on the right and left would show a comparable value, and the direct transmittance is therefore zero. To get accurate values, the visible part of the aureole of the diffuse sky model has to be added to the direct portion. Using this model to calculate the split, the data could then be fed into a simulation software. The calculation of the different non-horizontal planes involves the knowledge of the ground reflection (albedo). However, in Switzerland, the albedo can range from 0.14 for dry ground up to 0.8 for a fresh snow cover. With the proposed method, this change is taken into account
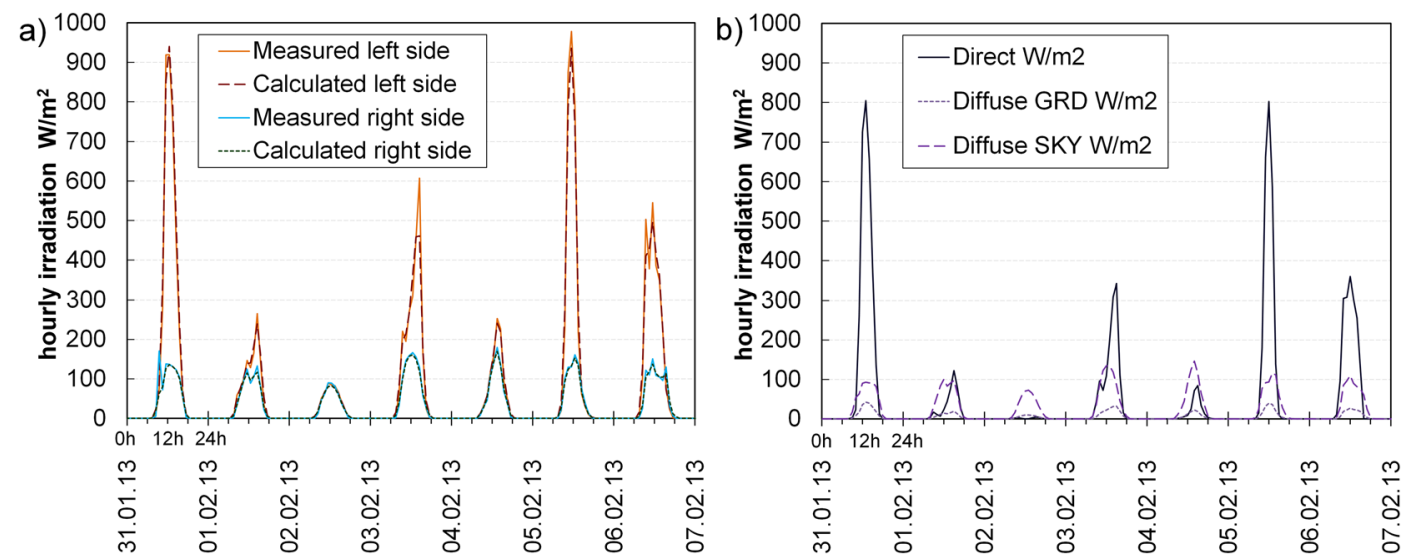

Fig. 12 a Total irradiations measured and calculated with the developed model on the vertical planes of the GEX. b Resulting split in direct and diffuse irradiation (from the ground and from the sky) 
since it is implicitly part of the measured vertical data, which means that no assumption on albedo is required. Also, the model allows the calculation in any tilted and oriented plane which can include tilted panoramic windows.

Figure 12a shows the comparison of the total solar irradiation on the vertical planes of the GEX, measured and calculated with the model described above for one selected week. Figure $12 \mathrm{~b}$ gives the calculated split between diffuse and direct solar irradiation. During this winter week, the snow cover changed both spatially and temporally. The fact that no assumptions were made regarding the albedo proved to be advantageous.

\section{Conclusion}

Detailed monitoring of the different energy consumers of a train revealed that the heating and cooling and other auxiliary systems (HVAC) represent about one third of the total energy consumption. These insights led us to investigate the impact of the solar gains on the HVAC energy consumption of a panoramic train. It was shown that the incoming energy due to the solar gains is in the same order of magnitude than the heating or cooling systems. It equates to 6 to $34 \%$ of all the energy consumed by the train, except the traction energy. Therefore, particular care should be taken when selecting the appropriate glazing in order to avoid overheating. However, in order to reduce the total energy consumption of the HVAC systems, one should not consider only the glazing. Thermal simulations indicate that the improvement of the overall insulation of the train envelope can lead to significant energy savings (18 to 26\%) in both cold and rather warm climates. Heat recovery systems are also an interesting alternative to reduce the energy consumption with a potential to save 25 to $32 \%$ of energy. It was also shown that for a warm climate, the difference in energy consumption when comparing a low solar gain or a high solar gain glazing is higher once the thermal insulation was improved and a heat recovery system installed. A judicious choice of the glazing can lead to 7 to $13 \%$ of energy savings depending on the climate. We hope these insights can contribute to design future trains with better thermal properties and lower energy consumption.

Acknowledgements We gratefully acknowledge Swisselectric Research SER for funding the project "Energy Efficiency of
Heating, Ventilation and Cooling in Public Transport" with financial support from the Swiss Federal Office of Energy SFOE and the Federal Office of Transport FOT. We are grateful to our railway company partners BLS and RhB for their help and made the measurement campaign possible. We thank our industrial partner AGC for providing us with glass samples. We are also thankful to all the academic partners involved in this project: University of Basel, Lucerne University of Applied Sciences an Arts and EMPA Dübendorf and SUPSI. We thank Samson Taylor for proof-reading. Moreover, we acknowledge the valuable contributions of Christoph Isenschmid (BLS AG), Hans Burkard (Opit Solutions AG) and Roland Steiner (Uni Basel) for technical support and providing the drawing of the window test bench and Leo Fäh (Rhätische Bahn AG) for providing the photograph of the GEX train.

\section{Compliance with ethical standards}

Conflict of interest The authors declare that they have no conflict of interest.

\section{References}

Barrero, R., Tackoen, X. \& Van Mierlo, J. 2008. Improving energy efficiency in public transport: stationary supercapacitor based energy storage systems for a metro network. in 1-8 (IEEE).

Bouvard, O., Lanini, M., Burnier, L., Witte, R., Cuttat, B., Salvadè, A., \& Schüler, A. (2017). Structured transparent low emissivity coatings with high microwave transmission. Applied Physics A., 123(1).

Burnier, L., Lanini, M., Bouvard, O., Scanferla, D., Varathan, A., Genoud, C., et al. (2017). Energy saving glazing with a wide band-pass FSS allowing mobile communication: upscaling and characterization. Antennas \& Propagation: IET Microwaves.

Daldaban, F., \& Ustkoyuncu, N. (2010). A novel linear switched reluctance motor for railway transportation systems. Energy Conversion and Management, 51, 465-469.

Duffie, J. A., \& Beckman, W. A. (1991). Solar engineering of thermal processes. Wiley.

EN 410:2011. Glass in building, Determination of luminous and solar characteristics of glazing. ISSN 0335-3931, AFNOR, 2011.

EN 673:2011. Glass in building, Determination of thermal transmittance (U value) Calculation method, eq. 1-5. ISSN 03353931, AFNOR, 2011.

Energie PANORAMA@ Bundesamt für Statistik, Februar 2014 www.bfs.admin.ch/bfs/portal/de/index/themen/08/01/pan. Document.118139.pdf

EQUA Simulation AB, 2016. IDA indoor climate and energy, version: 4.7.1. Solna, Sweden. www.equa.se

Erbs, D. G., Klein, S. A., \& Duffie, J. A. (1982). Estimation of the diffuse radiation fraction for hourly, daily and monthlyaverage global radiation. Solar Energy, 28(4), 293-302.

González-Gil, A., Palacin, R., \& Batty, P. (2013). Sustainable urban rail systems: strategies and technologies for optimal 
management of regenerative braking energy. Energy Conversion and Management, 75, 374-388.

González-Gil, A., Palacin, R., Batty, P., \& Powell, J. P. (2014). A systems approach to reduce urban rail energy consumption. Energy Conversion and Management, 80, 509-524.

Hamacek, Š., Bartłomiejczyk, M., Hrbáč, R., Mišák, S., \& Stýskala, V. (2014). Energy recovery effectiveness in trolleybus transport. Electric Power Systems Research, 112, 1-11.

Hoffrichter, A., Miller, A. R., Hillmansen, S., \& Roberts, C. (2012). Well-to-wheel analysis for electric, diesel and hydrogen traction for railways. Transportation Research Part D: Transport and Environment, 17, 28-34.

Isenschmid, C., Menth, S., \& Oelhafen, P. (2013). Energieverbrauch und Einsparpotential des S-Bahn Gliederzugs RABe 525 'Nina' der BLS AG. EisenbahnRevue, 398-403.

Perez, R., Seals, R., Ineichen, P., Stewart, R., \& Menicucci, D. (1987). A new simplified version of the Perez diffuse irradiance model for tilted surfaces, description, performance validation. Solar Energy, 39, 221-231.

Raghunathan, R. S., Kim, H.-D., \& Setoguchi, T. (2002). Aerodynamics of high-speed railway train. Progress in Aerospace Sciences, 38, 469-514.

Reber, G., et al. (2005). Angular dependent solar gain for insulating glasses from experimental optical and thermal data. Proc. of CISBAT. In EPFL www.glassdbase.ch/glassdocs/2211CISBAT2013 Reber.pdf.

Steiner R. et al., 2005. Experimental determination of spectral and angular dependent optical properties of insulating glasses. Proc. of CISBAT, EPFL. www.glassdbase. ch/glassdocs/2121-CISBAT2005_Oelhafen1Logo.pdf

Tzeng, G.-H., Lin, C.-W., \& Opricovic, S. (2005). Multi-criteria analysis of alternative-fuel buses for public transportation. Energy Policy, 33, 1373-1383.

Wood, R. M. Impact of advanced aerodynamic technology on transportation energy consumption. 2004. SAE International. 